\title{
Perancangan Sistem Informasi Pendaftaran Pasien Berbasis Web Dengan Fingerprint Di Puskesmas
}

\author{
Maria Meda Goda ${ }^{1}$, Mochammad Choirur Roziqin ${ }^{2}$, Sustin Farlinda ${ }^{3}$, Andri Permana Wicaksono ${ }^{4}$ \\ ${ }^{1}$ Jurusan Rekam Medik, Politeknik Negeri Jember \\ ${ }^{2}$ Jurusan Rekam Medik, Politeknik Negeri Jember \\ ${ }^{3}$ Jurusan Rekam Medik, Politeknik Negeri Jember \\ ${ }^{4}$ Jurusan Rekam Medik, Politeknik Negeri Jember \\ email: ${ }^{1}$ maia.wpn@ gmail.com, ${ }^{2}$ irul@polije.ac.id, ${ }^{3}$ Sustin@ polije.ac.id, ${ }^{4}$ andri_permana@polije.ac.id
}

\begin{abstract}
Puskesmas is a first-level and leading health care unit in the health care system tailored to the conditions, needs, demands, capabilities and innovations as well as local government policies. Generallythe data collection process at the puskesmas is still done manually, if the patient does not bring a Medical Index Card must wait a long time to get the file so it takes a long time in the service of patient registration. If the file is not found, a new file will be created which means that a duplicate data has occurred. The purpose of this research is to design and create a web-based patient registration information system with Fingerprint at Health Center. This research uses prototype method with qualitative research design. Data collection techniques carried out by researchers are observation, interview, and brainstorming. This research subject is the head of puskesmas,patient registration officer, and examination officer who input medical record data in puskesmas which each amounts to 1 person. The result of this study is a patient registration information system with fingerprint technology at the puskesmas. So that puskesmas can process data from one information system and able to improve the quality of service and is expected to facilitate users.
\end{abstract}

Keywords: health centers, information systems, fingerprint

\begin{abstract}
Abstrak
Puskesmas merupakan unit pelayanan kesehatan tingkat pertama dan terdepan dalam sistem pelayanan kesehatan yang disesuaikan dengan kondisi, kebutuhan, tuntutan, kemampuan dan inovasi serta kebijakan pemerintah daerah setempat. Umumnya proses pendataan pada puskesmas masih dikerjakan secara manual sehingga membutuhkan waktu yang lama dan jika pasien tidak membawa Kartu Index Berobat harus menunggu lama untuk mendapatkan berkasnya sehingga membutuhkan waktu yang lama dalam pelayanan pendaftaran pasien. Bila berkasnya tidak ditemukan, maka akan dibuatkan berkas baru yang berarti telah terjadi data rangkap. Rata-rata sebanyak $62 \%$ pasien tidak membawa Kartu Indeks Berobat(KIB) saat hendak berobat setiap harinya. Selain itu, dalam membuat laporan bulanan, petugas mencatat satu persatu data yang akan dibuat menjadi laporan bulanan. Tujuan penelitian ini merancang Program Sistem Informasi Pendaftaran pasien Berbasis Web dengan Fingerprint untuk mempermudah proses yang ada. Penelitian ini menggunakan metode prototype menurut referensi Sulianta meliputi: (1) Mengidentifikasi kebutuhan (2) Merancang Prototype (3) Mengkodekan prototype (4) Testing sistem (5) Menggunakan sistem. Hasil akhir perancangan tersebut menghasilkan Sistem Informasi pendaftaran pasien berbasis web dengan fingerprint untuk mempermudah mengolah data dan menyimpan data serta diharapkan akan memudahkan pengguna.
\end{abstract}

Kata kunci: puskesmas, sistem informasi, fingerprint

\section{Pendahuluan}

Puskesmas Surisina adalah salah satu fasilitas kesehatan tingkat pertama BPJS Kesehatan di Kabupaten Ngada. Puskesmas Surisina merupakan puskesmas yang menangani layanan kesehatan masyarakat, khususnya melayani pasien yang berada di Kecamatan Bajawa yang mencakupi enam desa dan daerah setempat yang masih masuk dalam wilayah Kabupaten Ngada. Puskesmas Surisina akan mengajukan akreditasi puskesmas pada tahun 2021 mendatang, sehingga puskesmas harus meningkatkan mutu pelayanan kesehatan dan pasien, meningkatkan perlindungan bagi sumber daya manusia dan meningkatkan kinerja puskesmas dan didukung dengan manajemen sistem pencatatan dan pelapor seperti yang tercantum dalam Akerditasi Puskesmas [1].
Puskesmas Surisina menyediakan fasilitas pelayanan rawat jalan dengan tiga kategori pasien, yaitu pasien umum, pasien BPJS Kesehatan dan pasien Jaminan Kesehatan Masyarakat Ngada (JKMN). Pasien umum merupakan warga atau masyarakat sekitar puskesmas yang tidak memiliki asuransi kesehatan, sedangkan untuk pasien BPJS Kesehatan dan pasien JKMN merupakan anggota dari penerima asuransi kesehatan yang berkerja sama dengan puskesmas. Berikut adalah data jumlah rata-rata kunjungan pasien umum, pasien BPJS dan pasien JKMN pada unit rawat jalan di Puseksmas Surisina.

Tabel 1. Data laporan kunjungan pasien rawat jalan pada Puskesmas Surisina Tahun 2019

\begin{tabular}{llll}
\hline Bulan & Jenis Kunjungan Pasien & Jumlah \\
& Umum JKMN BPJS & Kunjungan
\end{tabular}




\begin{tabular}{llllll}
\hline September & 311 & 343 & 57 & 711 & \\
Oktober & 298 & & 312 & 88 & 698 \\
November & 305 & & 249 & 89 & 643 \\
Desember & 312 & & 398 & 112 & 822 \\
\hline
\end{tabular}

Berdasarkan studi pendahuluan yang peneliti lakukan melalui observasi pada tanggal 20 Januari 2020 sampai 24 Januari 2020 bahwa Puskesmas Surisina buka pada hari Senin sampai Jumat. Penerimaan pasien di puskesmas pada setiap harinya (senin - jumat) berbeda - beda. Pasien terbanyak terletak pada hari senin, rabu dan kamis dengan rata- rata 50 pasien perhari. Dengan waktu pelayanan pendaftaran yang terbatas yaitu hanya 4 - 5 jam dalam satu hari dan hanya dilakukan oleh 1 (satu) orang petugas pendaftaran yang semua kegiatan pelayanan pendaftaran dilakukan sendiri, yaitu mulai dari melakukan verifikasi data pasien, mencari dokumen rekam medis pasien, memanggil pasien untuk menuju ke poli, mengantarkan dokumen rekam medis ke masing-masing poli hingga melakukan rekapan kunjungan harian puskesmas setiap harinya. Petugas loket pendaftaran menulis data pasien pada berkas Rekam Medis dan dicatat pada buku register kunjungan pasien, sehingga tidak adanya arsip yang dimuat dalam bentuk database. Hal ini terjadi karena Puskesmas Surisina belum memiliki sistem informasi pengolahan data pasien rawat jalan sehingga petugas harus menginputkan data kunjungan pasien, kedalam Microsoft excel secara manual setiap hari untuk dijadikan suatu laporan, dan informasi yang dihasilkan kurang tepat. Tidak adanya sistem informasi di Puskesmas Surisina dikarenakan sistem informasi yang dari Dinas Kesehatan hanya digunakan secara bertahap setiap tahun antar puskesmas satu dengan puskesmas yang lain, hal tersebut yang membuat Puskesmas Surisina tidak memiliki sistem informasi dalam mengolah data pasien rawat jalan. Setiap Puskesmas wajib melakukan kegiatan sistem informasi Puskesmas [2]. Di ketahui juga bahwa pada Puskesmas Surisina jika pasien yang tidak membawa Kartu Index Berobat (KIB) harus menunggu lama untuk mendapatkan berkasnya. Hal tersebut dapat mengakibatkan waktu tunggu pasien makin lama hingga 15-20 menit, sedangkan dalam ketentuan Tentang Standar Pelayanan minimal waktu penyediaan berkas rekam medis rawat jalan kurang lebih 10 menit [3]. Bila berkasnya tidak ditemukan, maka akan dibuatkan berkas baru yang berarti telah terjadi data rangkap. Permasalahan yang ditimbulkan akibat pasien tidak membawa KIB adalah terjadinya penduplikasian data dan antrian yang Panjang [4]. Pasien lama yang tidak membawa KIB akan diberikan nomor rekam medis baru saat mendaftar. Studi pendahuluan selama 1 minggu yang dilakukan peneliti di Puskesmas Surisina, terdapat 36 pasien tidak membawa Kartu Indeks Berobat (KIB) saat hendak berobat. Alasan para pasien berbeda-beda. Berikut jumlah alasan pasien tidak membawa Kartu
Indeks Berobat(KIB) yang di sajikan dalam diagram lingkaran pada gambar 1 berikut:

Alasan pasien tidak membawa KIB

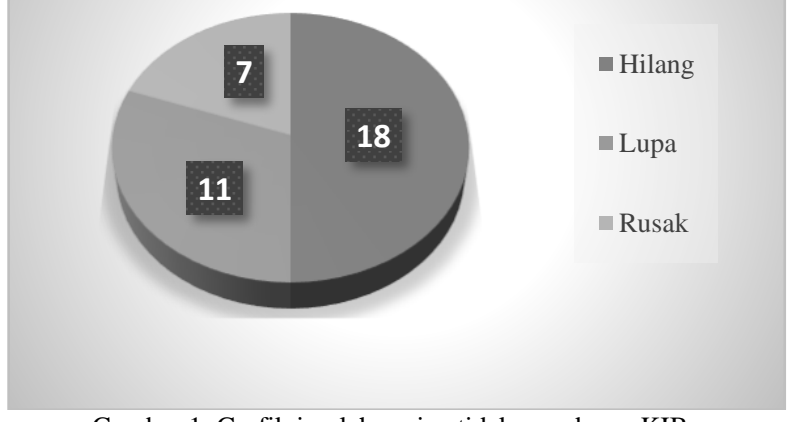

Gambar 1. Garfik jumlah pasien tidak membawa KIB

Grafik diatas dapat dilihat bahwa terdapat 18 pasien yang tidak membawa Kartu Indeks Berobat (KIB) karena Hilang, 11 pasien beralasan bahwa Kartu Indeks Berobat (KIB) lupa, dan 7 mengatakan bahwa Kartu Indeks Berobat (KIB) rusak.

Untuk meningkatkan pelayanan kesehatan kepada masyarakat puskesmas perlu melakukan pengembangan-pengembangan yang berkaitan dengan pengelolaan data dan informasi pasien dengan menggunakan sistem informasi pendaftaran pasien di puskesmas. Suatu teknologi yang mendukung dibutuhkan dalam mengatasi masalah tersebut diatas, seperti yang akan dibahas dalam penelitian ini yang berjudul"Perancangan dan Pembuatan Sistem Informasi Pendaftaran Pasien Berbasis Web Dengan Menggunakan Teknologi Finger Print di Puskesmas Surisina Kabupaten Ngada". Kelebihan sistem informasi yang akan dibuat oleh peneliti adalah adanya alat finger print, sistem ini disertai fitur login petugas menggunakan finger print untuk menjaga keamanan data dan petugas juga tidak perlu khawatir apabila ada pasien yang tidak membawa Kartu Indeks Berobat(KIB) dan pasien tidak perlu khawatir pula apabila Kartu Indeks Berobat(KIB) hilang. Alat finger print tersebut akan merekam sidik jari pasien yang akan berobat sebagai tanda pengenal yang secara otomatis akan tersimpan dalam sistem [5]-[6]. Dengan adanya sistem informasi pelayanan (komputerisasi) dengan fingerprint diharapkan dapat membantu petugas di Puskesmas Surisina. Bilamana dalam proses impelementasi terjadi error dengan alat fingerprint dapat diantisipasi dengan solusi sistem informasi manual dimana untuk pendaftaran pasien dengan menggunakan nomor induk keluarga (NIK) atau nomor rekam medis (RM) sedangkan untuk petugas pelayanan dengan menggunakan username dan password sehingga program dan proses pelayanan di puskesmas tetap berjalan serta menjamin data pasien tetap terjaga dengan baik. 


\section{Metode Penelitian}

Model perancangan sistem menggunakan prototyping model, yaitu model perancangan yang cepat dan pengujian terhadap model kerja (prototype) dari sistem baru melalui proses interaksi dan berulang-ulang yang biasa digunakan ahli sistem informasi [7]-[8]. Prototyping adalah proses iterative dalam pengembangan sistem dimana requirement diubah kedalam sistem yang bekerja (working system) yang secara terus menerus diperbaiki melalui kerjasama antara user dan analis [9]. Prototype juga bisa dibangun melalui beberapa tool pengembangan untuk menyederhanakan proses. Adapun tahapan tahapan dalam pengembangan dengan metode prototype ini yaitu pengumpulan kebutuhan, membangun prototyping, evaluasi prototyping, mengkodekan system, menguji system, evaluasi system, dan menggunakan sistem [10]. Berikut tahapan prototype dapat dilihat pada gambar 2 .

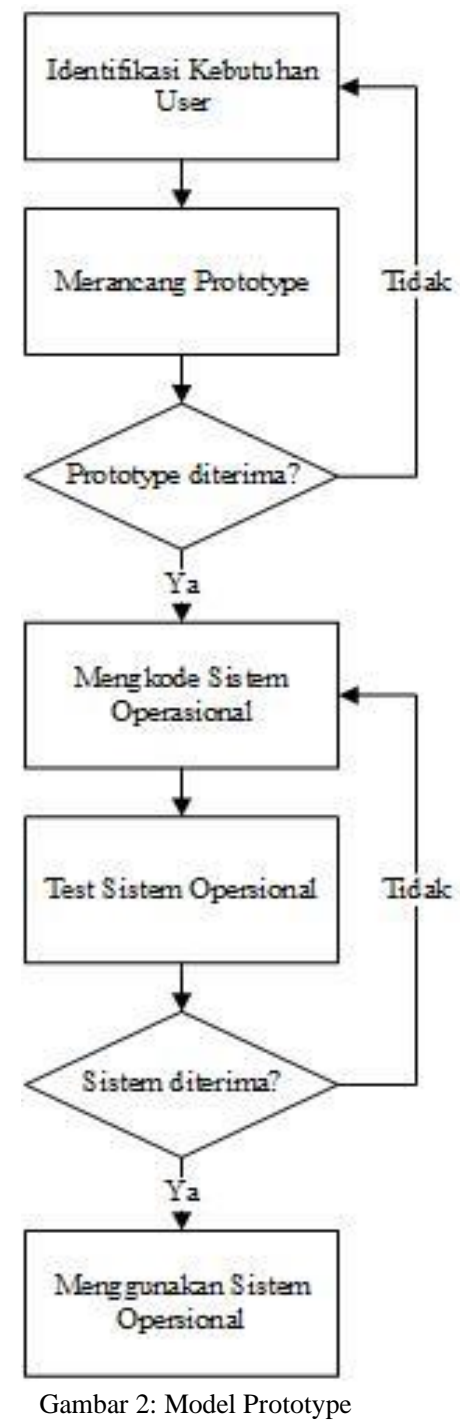

Penjelasan dari desain alur penelitian tersebut adalah:

a. Tahapan mengidentifikasi kebutuhan user dan pengumpulan data yang dibutuhkan dalam merancang Sistem Informasi Pendaftaran Pasien di Puskesmas Sursina Berbasis Web dengan teknologi Finger Print. Pengumpulan data diperoleh dengan cara wawancara observasi langsung terhadap data yang dibutuhkan. Data tersebut antara lain data petugas, data pasien, data penyakit, data tindakan dan data jenis pelayanan.

b. Tahap merancang Prototype. Pada tahapan ini peneliti membuat prototype program berupa membuat Flowchart, membuat DFD, membuat $E R D$, dan desain interface sederhana. Jika prototype yang dibangun diterima dan disepakati, maka peneliti dapat lanjut ke tahap c. Jika tidak maka peneliti harus mengulangi tahap a dan $b$. Pada metode ini menggunkan teknik wawancara untuk kesepakatan prototype yang telah dibangun

c. Tahap mengkode sistem. Pada tahap ini peneliti membangun sistem informasi berdasarkan prototype yang telah disepakati. pembangunan sistem informasi menggunakan bahasa pemrograman web.

d. Tahap Testing sistem. Pada tahap ini penelitian melakukan pengujian sistem informasi. Metode testing yang digunakan adalah metode blackbox dimana penguji hanya menguji berjalannya sistem informasi tanpa harus membuka dan melihat kode program. Setelah melakukan testing, peneliti mendemonstrasikan program ke user. Dan mempersilahkan user memberikan feedback dan menentukan apakah sistem informasi dapat diterima atau tidak. Tahapan ini menggunkan metode brainstorming yang dilakukan dengan pihak yang terlibat dalam penggunaan sistem. Jika diterima maka peneliti dapat melanjutkan ke tahap e. jika tidak diterima atau gagal dalam pengujian, maka peneliti harus mengulangi tahap c dan $\mathrm{d}$.

e. Menggunakan sistemTahap ini dapat menggunakan sistem informasi pendaftaran pasien berbasis web dengan menggunkan teknologi FingerPrint yang telah jadi di puskesmas.

Penelitian ini menggunakan kualitatif karena dalam teknik pengumpulan data yang dilakukan peneliti adalah observasi, wawancara, serta brainstorming. Adapun alat-alat yang digunakan dalam perancangan sistem informasi pendaftaran pasien di Puskesmas Surisina ini adalah terdiri dari perangkat keras dan perangkat lunak. Dalam perangkat keras (Hardware) terdiri dari laptop, mouse Logitech, RAM 4GB, Fingerprint solustion $x 100 \mathrm{c}$ sedangkan dalam reangkat lunak (software) terdiri dari sistem operasi Windows 10 64-bit, Microsoft Office Word 2019, Microsoft Office Visio 2019, Visual Studio Code, XAMPP Control Panel v3.2.2, PHP My Admin.

Dalam penelitian ini subjek penelitiannya adalah kepala puskesmas, petugas pendaftaran pasien rawat jalan yang berjumlah 1 orang dan petugas poli. Data dan informasi yang diperoleh dari hasil observasi, wawancara dan brainstorming akan menjadi bahan analisis. Hasil analisis berguna sebagai dasar dalam 
pembuatan sistem informasi. Sedangkan objek penelitiannya adalah Puskesmas Surisina Bajawa.

\section{Hasil dan Pembahasan}

\subsection{Analisis dan Perancangan}

Hasil diperoleh dari penelitian ini adalah sistem informasi pendaftaran pasien berbasis web dengan teknologi Fingerprint di puskesmas Surisina Bajawa. Permasalahan yang dihadapi di Puskesmas Surisina saat ini adalah semua kegiatan yang berlangsung di unit rawat jalan yaitu bagian pendaftaran pasien, pembayaran dan tiap poli pengerjaannya masih manual. Masalah datang ketika pasien berkunjung untuk berobat tanpa membawa kartu indeks berobat (KIB) yang diberikan pada awal pasien berobat [11]. Alur pelayanan rawat jalan berdasarkan observasi dan wawancara peneliti di Puskesmas Surisina Bajawa seperti berikut:

"Pasien datang mengambil nomor antrian di loket untuk di panggil sesuai nomor antrian, lalu petugas mendaftar pasien, apabila pasien tersebut pasien baru maka dibuatkan rekam medis baru dan diberikan kartu indeks berobat (KIB) dan memberikan motivasi agar kartu indeks berobat KIB tersebut dibawa setiap kali berobat di Puskesmas Surisina Bajawa, apabila pasien lama maka akan di cari berkas rekam medis pasien tersebut di rak penyimpanan sesuai nomor rekam medis yang tertera di kartu indeks berobat (KIB) yang sesuai dengan kode desa. Apabila pasien lama tersebut tidak membawa kartu indeks berobat (KIB), maka petugas mencari data pasien pada buku pasien sesuai desa/kelurahan berdasarkan nama kepala keluarga. Setelah itu petugas mencatat ke dalam buku register. Sebelum pasien mendapat layanan pemeriksaan di masing-masing poli, pasien terlebih dahulu melakukan pembayaran di bagian loket pendaftaran setelah itu Pasien menuju poli untuk menerima perawatan dari petugas poli. Petugas pemeriksa menulis penyakit dan tindakan pada dokumen rekam medik dan menyerahkan resep obat untuk pasien ke bagian farmasi. Setelah itu petugas pemeriksaan melakukan indeksing penyakit dan tindakan. Selesai jam pelayanan di loket pendaftaran dan pemeriksaan di poli petugas mengolah data menjadi laporan." Berikut flowchart manual Puskesmas surisina bajawa yang digunakan saat ini berdasarkan uraian alur diatas seperti pada gambar 3 dan 4 dibawah ini:

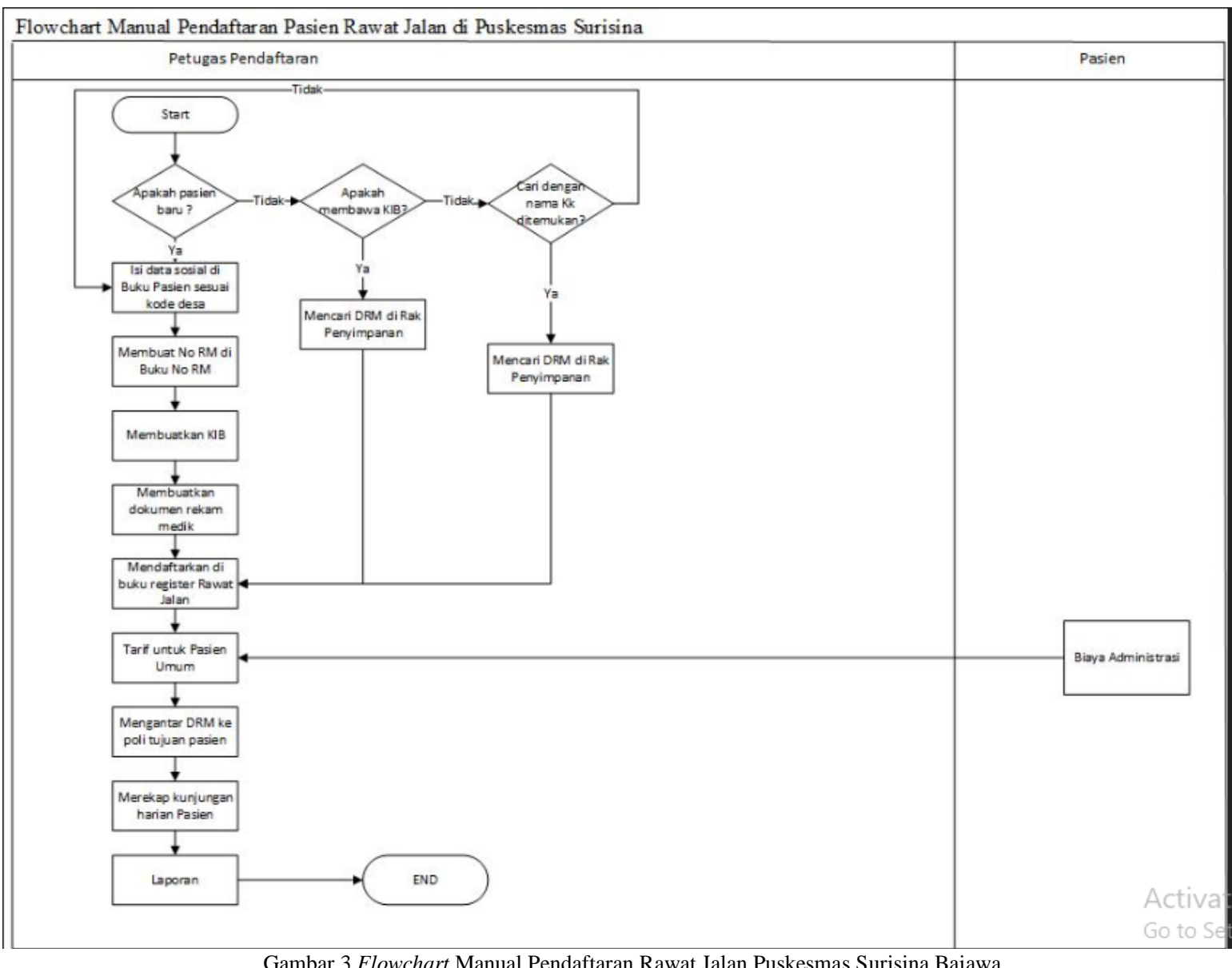

Gambar 3 Flowchart Manual Pendaftaran Rawat Jalan Puskesmas Surisina Bajawa 


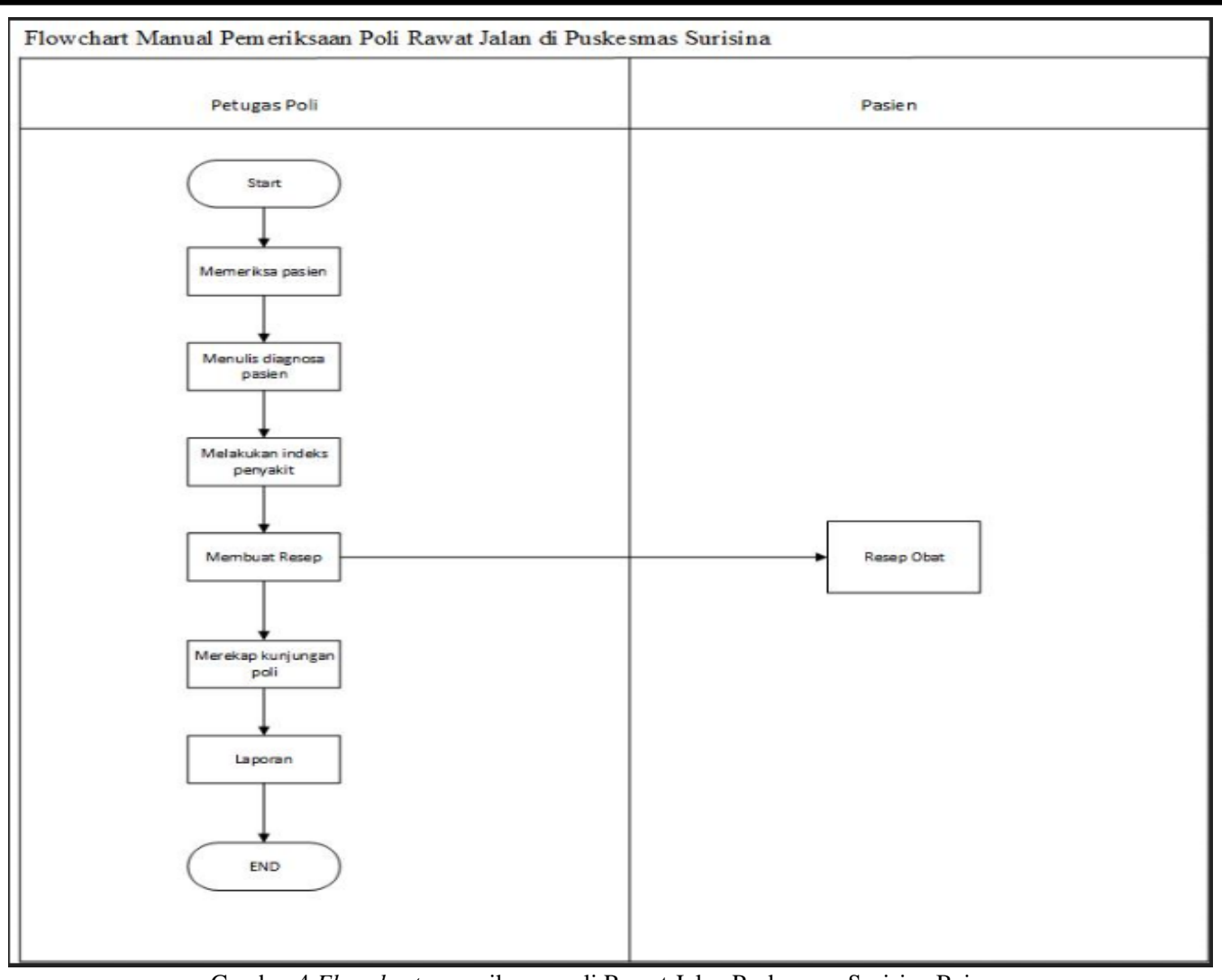

Gambar 4 Flowchart pemeriksaan poli Rawat Jalan Puskesmas Surisina Bajawa

Beberapa masalah yang terjadi berdasarkan uraian alur pelayanan diatas yaitu:

a. Pasien tidak membawa kartu indeks berobat (KIB) dengan alasan hilang, lupa dan rusak.

b. Apabila pasien tidak membawa kartu indeks berobat (KIB) maka petugas mencari nomor rekam medis pasien di buku register dengan menggunakan nama pasien dan tanggal terakhir berobat, sehingga menyulitkan petugas dalam pencarian.

c. Terdapat data ganda pada satu pasien akibat pasien yang tidak membawa kartu indeks berobat (KIB) tersebut dibuatkan dokumen baru untuk mempersingkat kerja petugas pendaftaran.

d. Dokumen rekam medik dibawa oleh petugas pendaftaran menuju poli, petugas pendaftaran yang hanya satu orang juga merangkap tugas menjadi distributor berkas ke poli sehingga pelayanan di loket pendaftaran terhambat.

e. Petugas harus merekap ulang jumlah pasien secara manual untuk di jadikan laporan.

Penyimpanan dokumen rekam medis di Puskesmas Surisina Bajawa menggunakan family folder. Sistem family folder adalah penyimpanan satu rekam medis digunakan oleh satu keluarga dan dimasing-masing formulir diberi kode khusus untuk menandai kode rekam medis ayah, ibu,anak dan keluarga. Sistem tersebut memudahkan petugas dalam mencari dokumen rekam medis di rak penyimpanan. Sehingga apabila pasien tidak mampu mendaftarkan diri (mengidentifikasi sidik jari) nya ke loket pendaftaran, maka keluarga lain dalam satu kartu keluarga dapat mewakilkan [12]. Hal ini dikarenakan pada sistem yang akan dibuat, nomor rekam medik fungsinya sama dengan nomor kartu keluarga. Sehingga dapat disimpulkan bahwa dengan masalah diatas, Puskesmas Surisina Bajawa membutuhkan sistem informasi yang berfungsi:

a. Dapat mencari data pasien lama dengan mudah, cepat, dan akurat yaitu dengan mesin fingerprint.

b. Dapat mendaftarkan anggota keluarga lain yang terdapat dalam satu kartu keluarga, dikarenakan nomor rekam medik fungsinya sama dengan nomor kartu keluarga.

c. Tampilan dan kerja yang sederhana (tidak berteletele) agar dapat mudah digunakan oleh user.

d. Dapat menampilkan dan mencetak laporan.

Dalam membuat sistem informasi menggunakan mesin fingerprint yang sesuai dengan kebutuhan petugas Puskesmas Surisina Bajawa, terdapat kebutuhan fungsional yang terdiri dari:

1. Sistem dapat mengolah data master:

a. Sistem dapat mengolah petugas

1) Data petugas meliputi Id, nama, jenis petugas, sidik jari atau username dan password.

2) Admin dapat mengelola data petugas seperti menambahkan, menyimpan, mengedit (ubah), menghapus, dan membatalkan proses sebelumnya.

b. Sistem dapat mengolah pasien

1) Data pasien meliputi data sosial pasien dan scan sidik jari yang akan disimpan di database fingerprint. 
2) Data fingerprint berisikan nomor rekam medik, nama pasien dan status sidik jari pada kolom besar dan yang membedakan data sidik jari pasien satu dengan yang lainnya

3) Admin dan petugas pendaftaran dapat mengolah data pasien dengan menambahkan, menyimpan, mengedit (ubah), menghapus, dan membatalkan proses sebelumnya serta mengidentifikasi dan menyimpan sidik jari pasien.

c. Sistem dapat mengolah jasa pelayanan

1) Data jasa pelayanan untuk pasien umum dilakukan oleh petugas pendaftaran di loket pendaftaran pasien.

2) Admin dapat mengolah data jasa pelayanan dengan menambahkan, menyimpan, mengedit (ubah), menghapus, dan membatalkan proses sebelumnya.

d. Sistem dapat mengolah penyakit

1) Data penyakit Id penyakit, kode penyakit, nama penyakit dan Id kategori dari data penyakit

2) Admin dapat mengolah data penyakit dengan menambahkan, menyimpan, mengedit (ubah), menghapus, dan membatalkan proses sebelumnya.

2. Sistem dapat mengolah data transaksi:

a. Sistem dapat mengolah data pendaftaran

1) Seluruh user dapat mengolah data pendaftaran ini, namun ada batasan untuk petugas pemeriksaan. Petugas pemeriksaan hanya dapat mengambil data pasien pada tabel (data grid view) saja untuk menampilkan data pasien tersebut di transaksi pemeriksaan

2) Data pendaftaran meliputi data sosial pasien sebagai identitas pasien terdapat nomor rekam medik dan nomor kunjungan, selain itu juga terdapat poli yang dituju beserta nomor urut pada poli, hari/tanggal kunjungan (tanggal hari ini), nama user, text box pencarian (dengan nomor rekam medik, nama pasien, dan nama kepala keluarga), identifikasi sidik jari beserta gambar sidik jarinya, serta tabel data grid view untuk menampilkan data pasien yang di cari

3) Data pendaftaran dapat ditambahkan, disimpan, diedit (ubah), dan di batalkan proses sebelumnya serta dapat mencari data pasien baik melalui nama, nomor rekam medik ataupun sidik jari

4) Hari/tanggal secara otomatis muncul hari dan tanggal hari ini

5) User secara otomatis muncul dari saat login

6) Nomor rekam medik secara otomatis muncul setelah menginputkan nama kepala keluarga

b. Sistem dapat mengolah data pemeriksaan

1) Admin dan petugas pemeriksaan dapat mengolah data pemeriksaan

2) Data pemeriksaan meliputi data pasien, hari/tanggal, user, data penyakit dan tindakan beserta kodenya yang di inputkan, serta biaya yang harus dibayar oleh pasien

3) Data pendaftaran dapat disimpan dan di batalkan proses sebelumnya

4) Kode diagnosa (penyakit) secara otomatis muncul ketika memilih data penyakit, begitu pula dengan kode tindakan akan secara otomatis muncul ketika memilih nama tindakan yang telah dilakukan oleh petugas pemeriksa di poli kepada pasien

5) Biaya akan muncul secara otomatis ketika memilih nama tindakan, jadi biaya dan kode tindakan akan muncul secara otomatis dan bersamaan.

3. Sistem dapat mengolah data laporan:

a. Sistem dapat mengolah data laporan bulanan

1) Hanya admin yang dapat mengolah data laporan bulanan

2) Dalam mengakses data laporan bulanan harus memilih periode waktu yang di inginkan agar dapat di olah laporan yang di inginkan meliputi laporan bulan ke berapa

3) Terdapat tombol cetak untuk mencetak laporan yang dikehendaki

b. Sistem dapat mengolah data laporan 10 besar penyakit

1) Hanya admin yang dapat mengolah data laporan 10 besar penyakit

2) Dalam mengakses data laporan 10 besar penyakit harus memilih periode waktu yang di inginkan agar dapat di olah laporan yang di inginkan meliputi laporan 10 besar penyakit dalam jangka waktu berapa bulan/tahun

3) Terdapat tombol tampil untuk menampilkan laporan dan tombol cetak untuk mencetak laporan yang dikehendaki

c. Sistem dapat mengolah data laporan kunjungan pasien

1) Hanya admin yang dapat mengolah data laporan kunjungan pasien

2) Dalam mengakses data laporan kunjungan pasien harus memilih periode waktu yang di inginkan agar dapat di olah laporan yang di inginkan meliputi kunjungan pasien dalam jangka waktu berapa bulan/tahun

3) Terdapat tombol tampil untuk menampilkan laporan dan tombol cetak untuk mencetak laporan yang dikehendaki.

\subsection{Perancangan Sistem}

Sistem informasi berbasis fingerprint untuk meningkatkan pelayanan pendaftaran pasien yang dikembangkan digambarkan melalui bagan seperti pada gambar 5 berikut: 


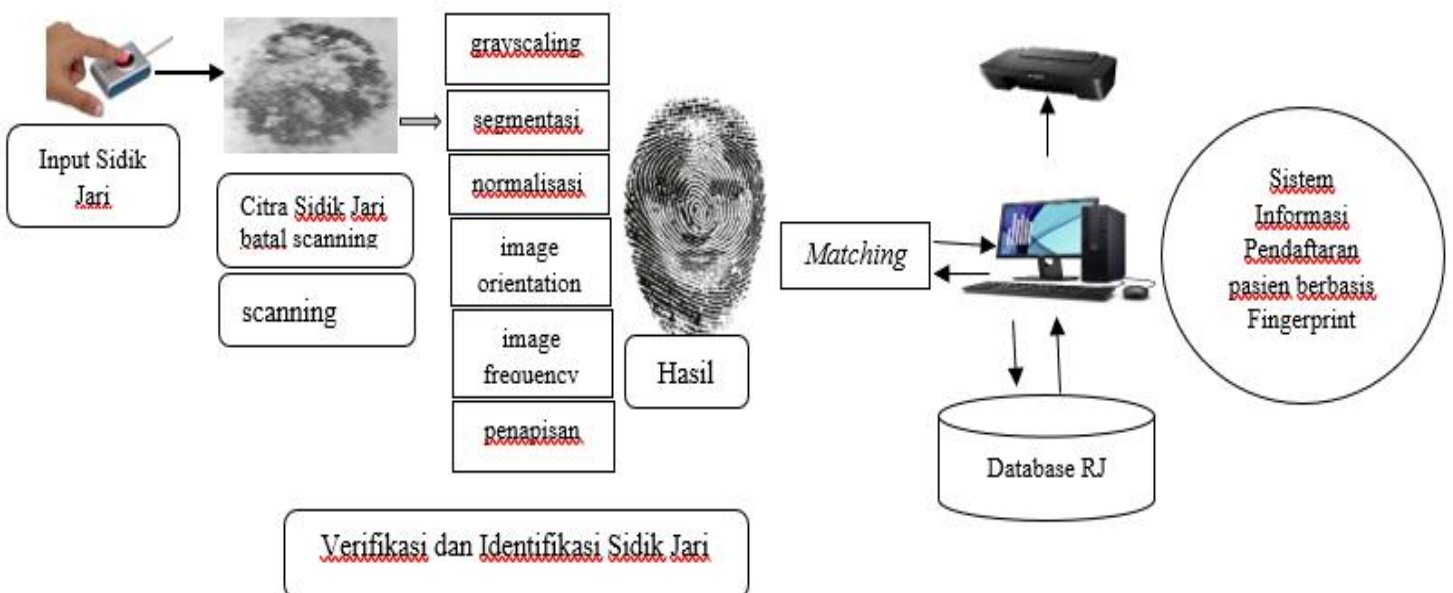

Gambar 5. Rancangan Sistem

Rancangan sistem informasi diatas ini menunjukan bahwa pasien yang mendaftar dating ke loket pendaftaran menempelkan jarinya ke mesin fingerprint untuk melakukan registrasi. Citra sidik jari pasien kemudian akan diidentifikasi dan diverifikasi oleh mesin fingerprint melalui beberapa tahap yaitu grayscaling, segmentasi, normalisasi, image orientation, image frequency dan penapisan [13]. Setelah melalui tahap perbaikan citra tersebut, mesin fingerprint akan melakukan proses matching antara citra sidik jari pasien dengan templates sidik jari yang tersimpan di database pendaftaran pasien. Proses matching ini akan menghasilkan keputusan apakah pasien tersebut merupakan pasien baru atau pasien lama. Apabila hasil matching cocok, maka pasein tersebut merupakan pasien lama dan data pasien akan secara otomatis ditampilkan pada layar komputer. Apabila hasil matching tidak cocok maka pasien tersebut merupakan pasien baru. Pasien kemudian didaftar sesuai dengan prosedur yang ada [14]. Alur sistem informasi berbasis fingerprint untuk meningkatkan pelayanan pendaftaran pasien rawat jalan juga dapat dilihat pada flowchart dokumen seperti gambar 6 berikut ini:

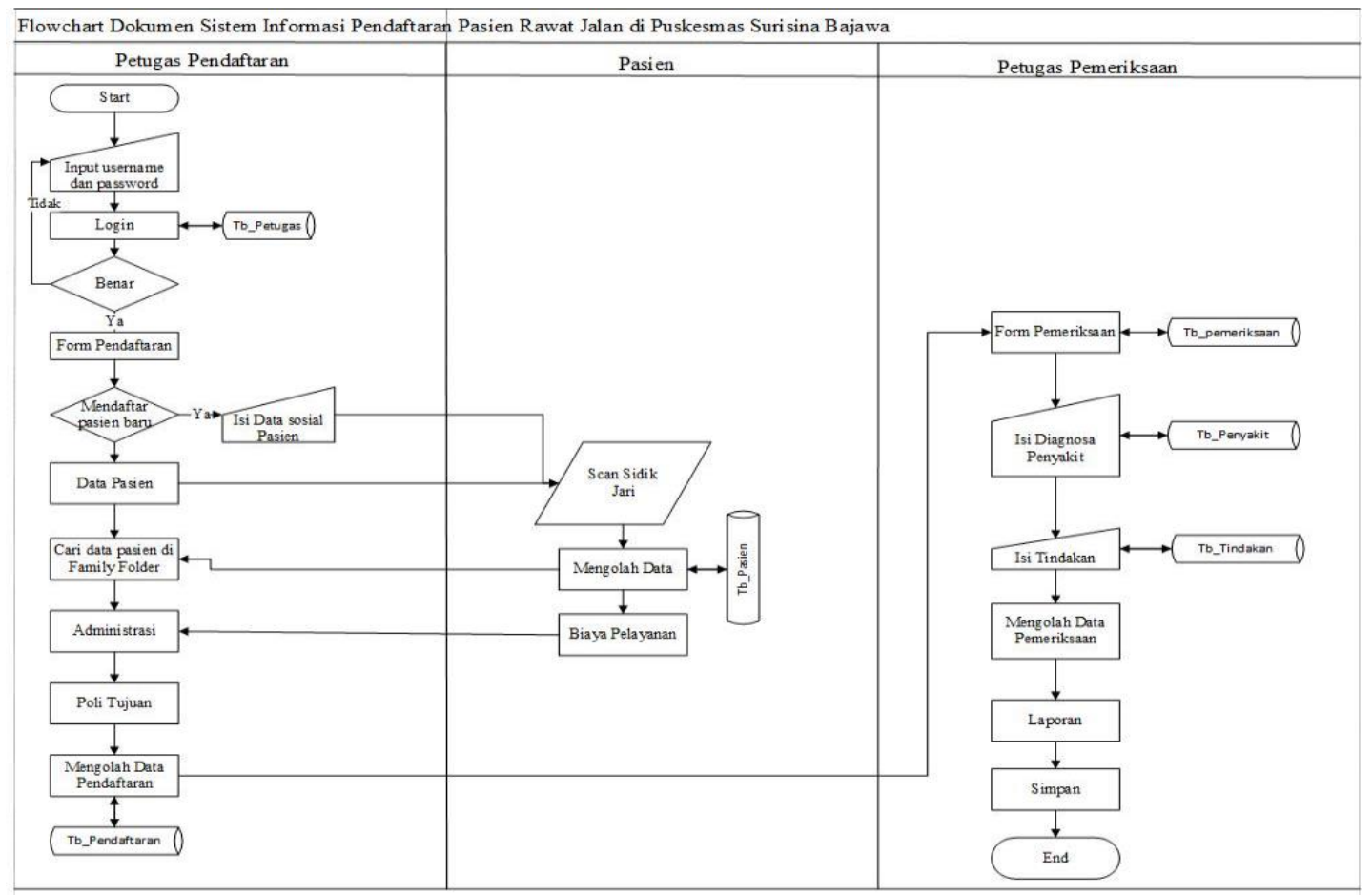

Gambar 6. Alur Sistem 
Berikut penjelasan mengenai flowchart sistem informasi pelayanan pendaftaran rawat jalan pada gambar flowchart diatas. Terdapat halaman Login untuk mengakses data master yang terdiri dari data petugas, data pasien, data penyakit, dan data jasa pelayanan. Dalam melakukan login terdapat hak akses yang berbeda di setiap user yaitu admin, Petugas pendaftaran, dan petugas pemeriksaan. Sistem dimulai dari petugas menginputkan username dan password masing-masing sesuai dengan hak aksesnya. Kemudian login, apabila salah maka akan ada notifikasi bahwa hak akses tidak sesuai ataupun username dan password salah. Apabila login berhasil maka akan muncul halaman awal. Petugas pendaftaran membukan form pendaftaran untuk mendaftarkan pasien rawat jalan. Jika pasien baru, maka petugas pendaftaran menanyakan data sosial berupa kartu tanda penduduk (KTP) atau wawancara secara langsung terhadap pasien dan atau keluarga pasien untuk di inputkan ke sistem. Setelah itu pasien melakukan scan sidik jari dengan bantuan petugas, data sidik jari tersebut akan tersimpan pada database yaitu di tb_pasien. Setelah itu petugas menyimpan data pasien, dan mendaftarkan sebagai pasien rawat jalan hari itu dengan memilih poli yang dituju dan disimpan pada database di tb_pendaftaran. Jika pasien lama, maka pasien melakukan scan sidik jari dengan panduan petugas pendaftaran. Kemudian data akan muncul di tabel family folder untuk menyatakan data pasien benar. Setelah itu petugas menginputkan poli dan jenis pasien untuk mengirim data ke form pemeriksaan. Setelah itu petugas pemeriksaan membuka form pemeriksaan untuk memasukkan data diagnosa penyakit dan tindakan. Data penyakit disimpan pada tb_penyakit, serta data tindakan disimpan pada tb_tindakan. Lalu petugas menyimpan data pasien setelah melakukan pemeriksaan dan disiimpan dalam database pada tb_pemeriksaan.

\subsection{Perancangan Proses}

Salah satu kompenen dalam serangkaian pembuatan perancangan sebuah sistem komputerisasi DFD menggambarkan aliran data dari sumber pemberi data masukan ke penerima data keluaran [15]. Perancangan proses sistem informasi berbasis fingerprint untuk meningkatkan pelayanan pendaftaran pasien rawat jalan disajikan dalam bentuk Diagram Konteks dan Diagram Level seperti pada gambar 7 berikut:

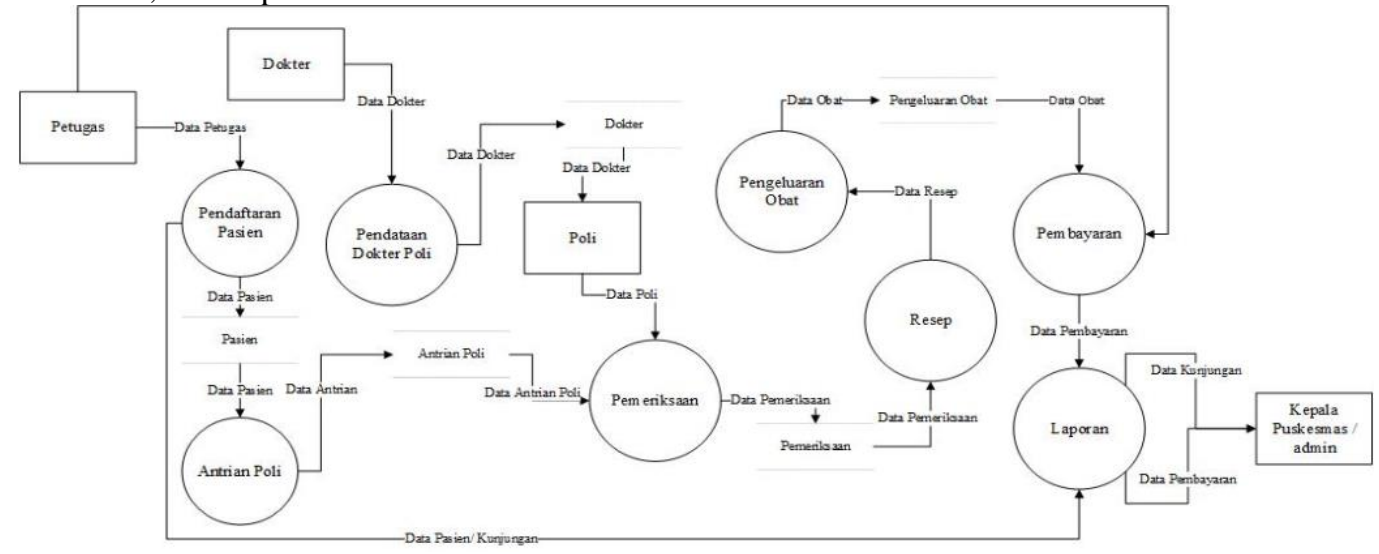

Gambar 7. Diagram Level

\subsection{Implementasi Sistem}

Sistem informasi berbasis fingerprint untuk meningkatkan pelayanan pendaftaran rawat jalan ini dibangun menggunakan bahasa pemrograman Visual Studio Code dengan database phpMyAdmin dan peralatan tambahan berupa fingerprint scanner. Form ini digunakan untuk menginputkan data transaksi pendaftaran pasien rawat jalan. Tampilan form pendaftaran seperti gambar 8 di bawah ini:

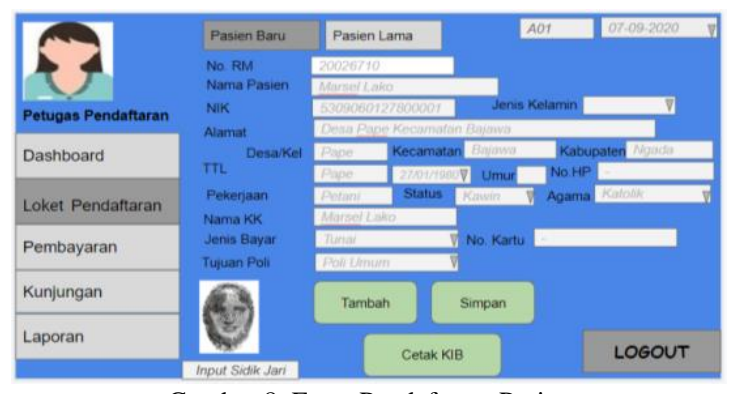

Gambar 8. Form Pendaftaran Pasien

Data pendataran pasien rawat jalan diinputkan ke form ini dengan menekan tombol Tambah kemudian pilih tombol simpan di sebelah kotak isian ID Finger untuk memverifikasi apakah sidik jari pasien sudah didaftarkan atau belum. Tampilan Form Verifikasi seperti pada gambar 9 berikut 


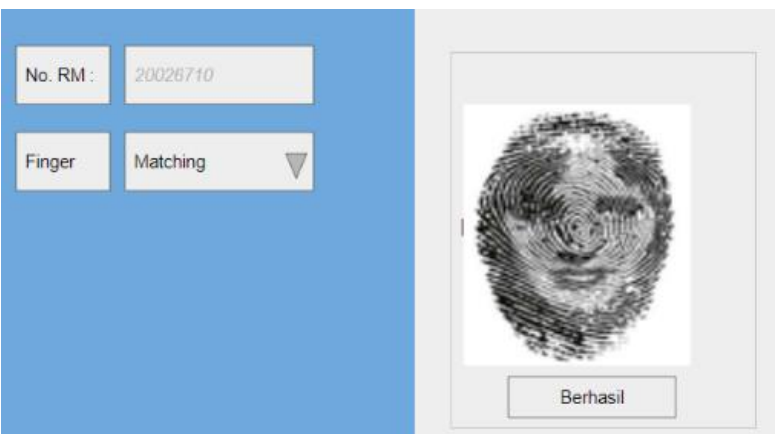

Gambar 9. Form Verifikasi sidik jari

Jika hasilnya macth (cocok), secara otomatis form pendaftaran akan terisi data pasien. Jika hasilnya not found (tidak ditemukan), akan muncul form registrasi data sidik jari. Tampilan form registrasi data sidik jari adalah seperti gambar 10 sebagai berikut:

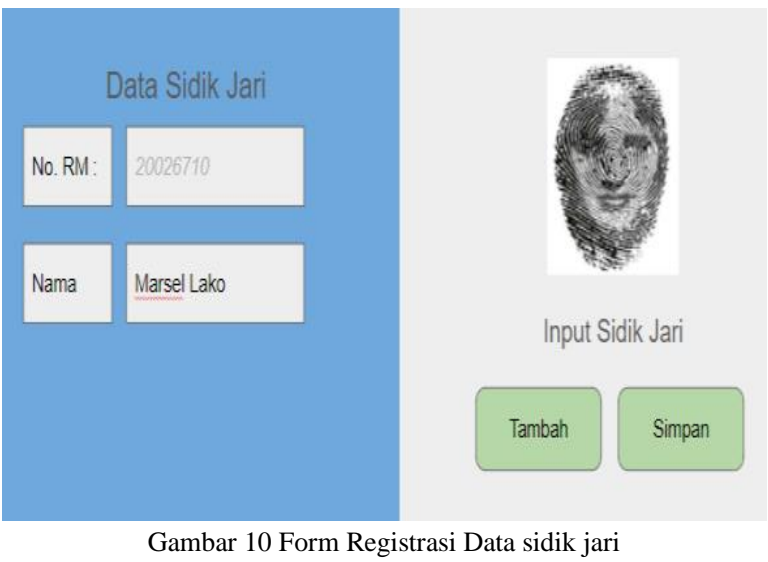

Setelah form registrasi data sidik jari tampil, klik tombol Tambah untuk menambah record data sidik jari. Nomor rekam medis dapat diisi dengan melakukan pencarian data pasien kemudian klik tombol Simpan.

\subsection{Hasil Implementasi Laporan Pendaftaran}

Laporan pendaftaran pasien rawat jalan menyediakan beberapa pilihan. Pilihan tersebut ditampilkan pada form laporan seperti gambar 11 berikut:

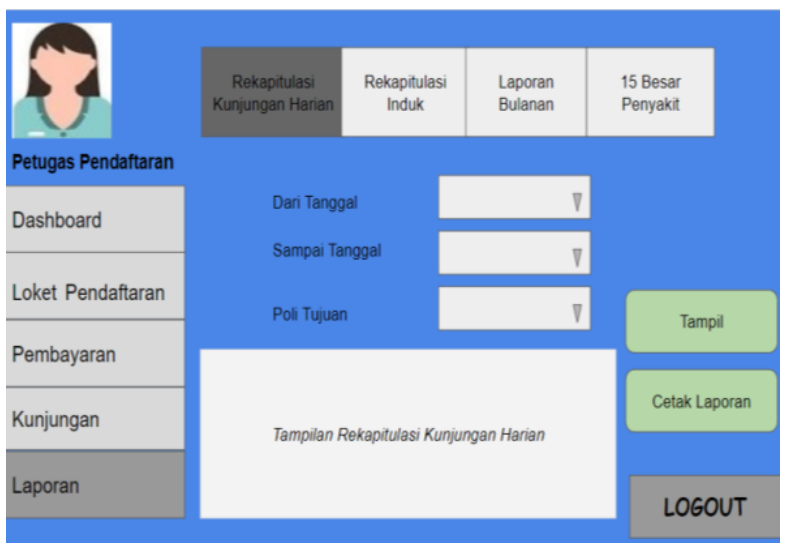

Gambar 11 Form Halaman Laporan Kunjungan Harian.

Gambar diatas merupakan halaman laporan jumlah kunjungan harian pada sistem sesuai dengan periode waktu yang di inginkan. Laporan tersebut meliputi jumlah menurut kunjungan atau pasien lama dan pasien baru, jumlah dengan jenis kunjungan dan jumlah kunjungan menurut poli sesuai dengan golongan umur. Berikut Form hasil laporan kunjungan poli umum pada puskesmas seperti pada gambar 12 berikut:

\begin{tabular}{|c|c|c|c|c|c|c|c|c|}
\hline \multirow{3}{*}{ No } & \multirow{3}{*}{ Elemen Data } & \multicolumn{4}{|c|}{ PUSKESMAS SURISINA } & \multirow{2}{*}{\multicolumn{2}{|c|}{ JUМLAH }} & \multirow{3}{*}{$\frac{\text { TOTAL }}{\mathrm{L}+\mathrm{P}}$} \\
\hline & & \multicolumn{2}{|c|}{$\mathrm{l}$} & \multicolumn{2}{|c|}{$p$} & & & \\
\hline & & Baru & Lama & Baru & Lama & $\mathrm{l}$ & $P$ & \\
\hline & Kelompok Umur Penguniung Poli Unum: & 209 & 34 & 292 & 36 & 243 & 328 & 571 \\
\hline 1 & 0.7 hari & & & & & . & & \\
\hline 2 & 8.28 hari & & & & &. & . & . \\
\hline 3 & $29 \cdot<1$ tatun & 5 & 2 & 15 & 4 & 7 & 19 & 26 \\
\hline 4 & $1-<5$ tatun & 14 & 3 & 18 & & 17 & 18 & 35 \\
\hline 5 & $5-9$ thiun & 25 & 7 & 24 & 1 & 32 & 31 & 63 \\
\hline 6 & $10-16$ tatun & 38 & 10 & 53 & 4 & 48 & 57 & 105 \\
\hline 7 & $15-19$ tatun & 36 & 9 & 68 & 13 & 45 & 81 & 126 \\
\hline 8 & $20-44$ tahun & 47 & 2 & 56 & 8 & 49 & 64 & 113 \\
\hline 9 & $45-54$ tatun & 17 & 1 & 23 & & 18 & 23 & 41 \\
\hline 10 & 55 - 59 tatun & 13 & & 17 & & 13 & 17 & 30 \\
\hline 11 & $60-69$ tatun & 9 & & 12 & & 9 & 12 & 21 \\
\hline 12 & 370 tahun & 5 & & 6 & & 5 & 6 & 11 \\
\hline III & Kategori Penduduk: & 209 & 34 & 292 & 36 & 243 & 328 & 571 \\
\hline 1 & Keluarga miskin & 48 & 14 & 74 & 12 & 62 & 86 & 148 \\
\hline 2 & Buvan keluarga mistin & 161 & 20 & 218 & 24 & 181 & 242 & 423 \\
\hline
\end{tabular}

\section{Kesimpulan}

Sistem informasi berbasis fingerprint yang dibangun dengan menggunakan bahasa pemrograman Visual Studio Code dengan database mysql. phpmyadmin dan peralatan tambahan berupa fingerprint scanner ini telah berjalan dengan baik dan dapat mengatasi ketidakakuratan dalam pencarian data pasien serta mampu mempercepat proses pelayanan pendafataran pasien rawat jalan di puskesmas.

\section{DAFTAR PUSTAKA}

[1] Molyadi and L. Trisnantoro, "PELAKSANAAN KEBIJAKAN AKREDITASI PUSKESMAS DI KABUPATEN KUBU RAYA,” J. Kebijak. Kesehat. Indones. JKKI, vol. 07, pp. 18-23, 2018.

[2] S. Farlinda, F. Hikmah, and I. Saputri, "Pengembangan Website Rumah Sakit Paru JemberSebagai Media Promosi Pelayanan KesehatanMasyarakat," J. Semnaskit, vol. 1, no. 1, pp. 225-230, 2015, doi: 10.1017/CBO9781107415324.004.

[3] M. Maulana, "Inovasi Sistem Informasi Pendaftaran Pasien Dengan Scanner Kib Dan Mesin Antrian Elektronik," $J$. Rekam Med. Dan Inf. Kesehat., vol. Vol. 1 No., 2019.

[4] S. Amanda, Esa, R. Wijayanti Adi, A. Deharja, and Selvia Juwita, "ANALISIS FAKTOR PENYEBAB TERJADINYA DUPLIKASI NOMOR REKAM MEDIS RAWAT JALAN DI PUSKESMAS KENCONG KABUPATEN JEMBER," $J$. Rekam Med. Dan Inf. Kesehat., vol. Vol 1, no. E-ISSN: 2721866X, 2020.

[5] B. N. Sugiyanto, Kusworo Adi, "Aplikasi Terminal Sidik Jari Dalam Pemantauan Imunisasi Balita," J. Sist. Inf. Bisnis 03, 2011.

[6] R. Wulandari, A. Febriani, and U. Rahmalisa, "SISTEM INFORMASI PRESENSI FINGERPRINT DIKTENDIK BERBASIS WEB (STUDI KASUS : MA AR-ROSYIDIYAH BENGKALIS)," JIP (Jurnal Inform. Polinema), vol. 6 No 1, 
no. ISSN: 2614-6371 E-ISSN: 2407-070X, 2019, doi https://doi.org/10.33795/jip.v6i1.272.

[7] R. N. Karimah and A. P. Wicaksono, "Prototype Sistem Informasi Pelayanan Bayi Baru Lahir pada Fasilitas Kesehatan Primer," Khazanah Inform. J. Ilmu Komput. dan Inform., vol. 4, no. 1, p. 16, 2018, doi: 10.23917/khif.v4i1.5330.

[8] Anastasia Meyliana, "Perancangan Sistem Informasi Presensi Karyawan Dengan Metode Prototype Menggunakan Fingerprint," J. Speed - Sentra Penelit. Eng. dan Edukasi, vol. 12 No 2, 2020

[9] F. Susanto, "Sistem informasi pengolahan data pasien pada puskesmas abung pekurun menggunakan metode prototype," J. Mikrotik, vol. 8, no. 1, pp. 65-73, 2018, [Online]. Available: https://ojs.ummetro.ac.id/index.php/mikrotik/article/view/751 1552 .

[10] Muharto and Ambarita, Metode Penelitian Sistem Informasi: Mengatasi Kesulitan Mahasiswa Dalam Menyusun Proposal Penelitian. CV. Budi Utama ISBN:978-602-401-475-9, 2016.

[11] M. Maulana, "Inovasi Sistem Informasi Pendaftaran Pasien Dengan Scanner Kib Dan Mesin Antrian Elektronik," $J$. Rekam Med. Dan Inf. Kesehat., vol. Vol 1, 2019.
[12] L. Y. Catur Fifti Anas Sari, "Perancangan Sistem Informasi Absensi Menggunakan Finger Print di Badan Perencanaan Pembangunan Daerah dan Penanaman Modal Kabupaten Pacitan," J. Nas. Inform. dan Komput. FTI UNSA, 2013.

[13] W. M. Tominanto, "SISTEM INFORMASI BERBASIS FINGERPRINT UNTUK MENINGKATKAN PELAYANAN PENDAFTARAN PASIEN RAWAT JALAN," J. Infokes, vol. 3 NO. 2, no. 2086-2628, 2013.

[14] F. S. dan R. P. W. Noval Aditya Muhammad, "Pembuatan Aplikasi Presensi Perkuliahan Berbasis Fingerprint (Studi Kasus : Jurusan Sistem Informasi Institut Teknologi Sepuluh Nopember Surabaya)," J. Tek. POMITS, vol. Vol. 2, No, no. ISSN: 2337-3539 (2301-9271 Print), 2013, doi: http://dx.doi.org/10.12962/j23373539.v2i3.5160.

[15] Y. Puspitasari and S. Iriani, "SISTEM INFORMASI REKAM MEDIS PASIEN RAWAT JALAN PADA PUSKESMAS PRINGKUKU KABUPATEN PACITAN," IJCSS - Indones. J. Comput. Sci. - Speed - FTI UNSA - ijcss.unsa.ac.id, no. ISSN : 1979-9330 (Print)-2088-0154 (Online)-2088-0162 (CDROM), 2013, doi: http://dx.doi.org/10.1123/ijns.v4i3.265. 